\title{
Molecular Study of Energy Related Mitochondrial Genes in Arabian and Bactrian Camels
}

\author{
${ }^{1,2}$ Mohamed M. Ahmed, ${ }^{1,3}$ Samir A. El-Shazly, ${ }^{1,5}$ Samy M. Sayed and ${ }^{4,6}$ Sayed A.M. Amer \\ ${ }^{1}$ Department of Biotechnology, Faculty of Science, Taif University, Taif, Saudi Arabia \\ ${ }^{2}$ Department of Biochemistry, Faculty of Veterinary Medicine, Minufiya University, Sadat City, Egypt \\ ${ }^{3}$ Department of Biochemistry, Faculty of Veterinary Medicine, Kafrelsheikh University, Kafrelsheikh, Egypt \\ ${ }^{4}$ Department of Biology, Faculty of Science, Taif University, Taif, Saudi Arabia \\ ${ }^{5}$ Department of Entomology, Faculty of Agriculture, Cairo University, Cairo, Egypt \\ ${ }^{6}$ Department of Zoology, Faculty of Science, Cairo University, Cairo, Egypt
}

Received 2012-10-10, Revised 2013-02-11; Accepted 2013-02-26

\begin{abstract}
The single-humped camel, Camelus dromedaries inhabiting Afro-Arabia and the double-humped camel, Camelus bactrianus inhabiting central Asia are the only species in their genus. The present study aimed to amplify and partially sequence the mitochondrial DNA genes encoding for NADH dehydrogenase subunit 1, cytochrome c oxidase subunit 1 , ATP synthase subunit 6 (ATP6), cytochrome b and displacement region (d-loop) in the single-humped camel and compare it to their counterparts already sequenced for the doublehumped camel. These energy-related genes showed amino acid substitutions gradually increased according to their locations among macromolecular energy transducers. Both ATP synthase 6 in the central core and cytochrome $\mathrm{b}$ in the inner mitochondrial membrane acquired the greatest substitutions of 5 and 7 amino acids, respectively. Cytochrome c oxidase is the terminal complex of the electron transport chain of the inner mitochondrial membrane and it showed no substitutions. These substitutions seemed to be correlated with the energy metabolism in both camel phenotypes. The d-loop showed tandem repeats of six nucleotides at its $3^{\wedge}$ end with polymorphism between both species without any evidence relates such variation to energy production.
\end{abstract}

Keywords: Energy, Genes, Arabian, Bactrian, Camels

\section{INTRODUCTION}

The genus Camelus posseses two species, the singlehumped Camelus dromedaries and the double-humped Camelus bactrianus. The first inhabits Afro-Arabia while the second inhabits Central Asia. Camel has been historically and economically an important species worldwide especially in the Arabian Peninsula where Saudi camels comprise $16 \%$ of the animal biomass (AlSwailem et al., 2010). Both Bactrian and Arabian camels live in desert areas. The geographic range for Arabian camel is Northern Africa and the Middle East. The Arabian camel overlaps with the Bactrian one in the areas of Afghanistan, Pakistan and Southwest Asia (Burton, 1972; Cockrill, 1984).
Camel stores its energy reserves in the form of fat in different body fat depots of which the hump and abdomen depots comprise a considerable amount of the adult body weight and their fats contain mixtures of fatty acids (Emmanuel and Nahapetian, 1980; Kadim et al., 2002). Camel has unique characteristics enable it to adapt its desert environment such as fluctuation of its body temperature, tolerance of water loss and capability of drinking more water in little time (Schmidt-Nielsen, 1979). The physiology of camel is also unique and interesting (Holler et al., 1989; Shirazi-Beechy et al., 1994; Elmahdi et al., 1997; Zierath et al., 1998; Abdel-Fattah et al., 1999; Kaske et al., 2001; Duehlmeier et al., 2007) so that it needs further biological investigation.

Corresponding Author: Sayed A.M. Amer, Department of Biology, Faculty of Science, Taif University, Taif, Saudi Arabia 
Despite its economical, cultural and biological importance, the molecular study targeting camel genome is limited and there is no much available information about the camel genome especially for Arabian camel. The present study focused on sequencing some mitochondrial genes related to energy metabolism such as NADH subunit 1 (ND1), cytochrome oxidase subunit 1 (CO1), ATP synthase 6 (ATP6), cytochrome b (cytb) and displacement region (d-loop).

Several proteins are involved in oxidative phosphorylation and encoded by mitochondrial DNA genes. Among these genes are ND1, CO1, ATP6 and cytb (Fonseca et al., 2008).

Respiratory complex I (NADH: quinone oxidoreductase) is an entry point to the electron transport chain in mitochondria. It couples NADH oxidation and quinone reduction to proton translocation across the inner mitochondrial (or plasma) membrane, so it is central to energy transduction (Bridges et al., 2010). Complex I dysfunctions are linked to an increasing number of neuromuscular and neurodegenerative diseases as well as to oxidative stress and aging (DiMauro and Schon, 2003).

$\mathrm{CO} 1$ is the terminal complex in the electron transport chain and is located in the inner mitochondrial membrane. The core subunits of CO1 (subunits I, II and III) are encoded by the mitochondrial genome. CO1 activity acts to prevent an excessive buildup of reactive oxygen species (Chen et al., 2009).

ATP synthase is one of the most important molecular motors of the living cell. It occupies a special location among macromolecular energy transducers. One type of ATP synthase protein complexes performs synthesis of the overwhelming majority of ATP molecules in the cell (Skulachev, 1988; Nicholls, 2002; Nelson and Cox, 2004). These molecules are the smallest macromolecular electric motors in nature (Romanovsky and Tikhonov, 2010).

Mitochondrial cytb is conserved hydrophobic protein containing eight or nine transmembrane domains and two heme groups. To date, about 27 different mutations have been identified in cytochrome b, mostly in patients with skeletal muscle weakness and exercise intolerance (Andreu et al., 1999; Fernandez-Vizarra et al., 2007).

The signature form of mammalian mtDNA is the dloop molecule, which maintains a short piece of the Heavy $(\mathrm{H})$ strand at the origin of replication. The d-loop is thus defined as a three-stranded structure with the nascent leading $\mathrm{H}$ strand defining the origin of leading-strand replication $(\mathrm{OH})$ at its 5 , end. D-loop strands are variable in size in a species-specific manner and are turned over more rapidly than the rate of genomic replication would require (Clayton, 1996).

In our proposed study, we aimed to investigate the genetic differences between the Arabian and Bactrian camels in the respect to mitochondrial genes responsible for energy production (ND1, CO1, ATP6, Cytb and dloop). The proposed study may also provide valuable information for Arabian camel genetics.

\section{MATERIALS AND METHODS}

Blood samples were withdrawn into heparinized tubes from the jugular vein of 10 different Arabian camel males from production breed at slaughter house (Taif, KSA). Similarly, for racing breed, blood samples were collected from 5 different individuals from a private local farm after taking the owner's permission. Different blood samples were numbered and labeled with full information.

Mitochondrial DNA was extracted from $0.5 \mathrm{~mL}$ blood samples with QIAGEN spin-column kits according to the manufacturer's instruction (QIAamp DNA Micro Kit). Extracted DNA concentration and quality were determined spectrophotmetrically at $260 / 280 \mathrm{~nm}$ and was used for Polymerase Chain Reaction (PCR).

PCR was conducted in a final volume of $50 \mu \mathrm{L}$ containing $2 \mu \mathrm{L}$ DNA template and $2 \mu \mathrm{L}$ of 10 picomolar forward primer, $2 \mu \mathrm{L}$ of 10 picomolar reverse primer of the corresponding genes as listed in Table 1 and $25 \mu \mathrm{L}$ PCR master mix (Promega Corporation, Madison, WI) and $19 \mu \mathrm{L}$ autoclaved deionized distilled water. PCR was carried out using a PeX 0.5 thermal Cycler with the cycle sequence at $94^{\circ} \mathrm{C}$ for $4 \mathrm{~min}$ one cycle, followed by 40 cycles each of which consisted of denaturation at $94^{\circ} \mathrm{C}$ for one min, annealing at corresponding specific temperature (as shown in Table 1) for one min and extension at $72^{\circ} \mathrm{C}$ for one min with a final strand elongation for one cycle at $72^{\circ} \mathrm{C}$ was done for an additional $5 \mathrm{~min}$. The PCR products were analyzed in $1 \%$ agarose gel electrophoresis in TAE buffer $(40 \mathrm{~mm}$ Tris, $40 \mathrm{mM}$ acetic acid and $1 \mathrm{mM}$ ethylenediamine-tetra acetic acid) with ethidium bromide staining. 100bp DNA ladder (Biolabs) was used as a molecular marker. Then PCR products bands were visualized under UV light and photographed. The PCR products were then excised from agarose gels and purified using spin column (BioFlux, Tokyo, Japan) according to the manufacturer's instructions and sequenced in an ABI PRISM 3730 $\times 1$ sequencer (Applied BioSystems) and BigDyeTM Terminator Sequencing Kits with AmpliTaqDNA polymerase (FS enzyme) (Applied Biosystems) following the protocols supplied by the manufacturer. 
Mohamed M. Ahmed / American Journal of Biochemistry and Biotechnology 9 (1) (2013) 61-70

Table 1. Primers designed and used for PCR amplification and sequencing. Annealing temperature refers to that of the conducted PCR to obtain the amplified fragments

\begin{tabular}{lllc}
\hline Gene & Primer name & Sequence $\left(5^{`}-3^{\prime}\right)$ & Annealing temperature $\left({ }^{\circ} \mathrm{C}\right)$ \\
\hline ND1 & Camel ND1-F & AGTAGAACGAAAAGTCCTAG & 49 \\
& Camel ND2-R & TTAATTCTTGGATGATTATTC & 54 \\
CO1 & Camel CO1-F & CTATGTTCATTACTCGCTGA & 5 \\
& Camel CO1-R & GATGTTGCCTCCATGGAGTG & 52 \\
ATP6 & Camel ATP6-F & CCCTACAGTAATAGGACTTC & 54 \\
& Camel ATP6-R & GTCATGTAAATACAGGCT & 50 \\
Cytb & Camel cytb-F & GACAAACATCCGAAAATCACAC & 5 \\
& Camel cytb-R & CTTCATTTTAGGATACGGTT & 5 \\
& Camel d-loop-F & AAAACGGCAATAGCCCTTGAG & \\
& Camel d-loop-R & GCCCCCGTAAAATTGCTGTT & \\
\hline
\end{tabular}

After reading the targeted genes, the nucleotide sequences have been treated with different software programs (DNASIS, MacClade, PAUP) that enabled us to detect genetic relatedness between different samples. The same genes for the single-humped camel from Morocco and Dubai and the double-humped Bactrian camel were obtained from the Genbank database with their accession numbers JN632608 (Hassanin et al., 2012), NC 009849 (Huang et al., 2007), NC_009628 (Ji et al., 2009 ) to be compared to the Saudi breed samples.

\section{RESULTS}

In this study, unambiguous nucleotides of 783, 789, 550, 966 and 570 bp from ND1, CO1, ATP6, cytb genes and d-loop, respectively, were sequenced for 10 individuals of the Arabian production camel and 5 individuals of the Arabian racing camel. These data were deposited in DDBJ/EMBL GenBank database with their accession numbers (AB753101-AB753161). In order to estimate the base composition and frequencies for the obtained sequences, the data were concatenated and the gab-containing sites were deleted so that 3658 bp were left for analysis. The data showed base frequencies of A $=27.75 \%, \mathrm{C}=27.89, \mathrm{~T}=27.97$ and $\mathrm{G}=16.38$.

The sequenced fragments of the studied genes and the intra and inter-specific nucleotide and amino acid substitutions were summerized in Table 2. Seven hundred eighty three nucleotides from ND1 gene showed 54 base substitutions between Arabian and Bactrian camels of which only one non-synonymous base transition (A-G) has been recorded which involved a substitution of serine with asparagine $A_{470} \rightarrow G_{470}$ at the second position of their codon (Fig. 1). The other 53 substitutions were synonymous and involved 49 transitions and 4 transversions. There was no base changes among the 15 studied Arabian camel individuals either for production or racing (data not shown).
For the barcoding gene encoding for $\mathrm{CO} 1$, the sequenced nucleotides of $789 \mathrm{bp}$ contained 51 base substitutions between Arabian and Bacterian camels (data not shown) without non-synonymous changes (Fig. 2). Of these substitutions, 47 were transitions (A-G and C-T) while only 4 were transversions (purines to pyrimidines and vice versa). Among the Arabian samples (either racing or production) there were 6 synonymous transitions.

The polymorphism of the 550 base pair representing the partial sequence of the ATP6 gene in 15 Arabian camel individuals and the Bacterian camel was analyzed. Forty substitutions were recorded between the two species of which 38 were transitions and only 2 were transversions. Within these substitutions, 5 were nonsynonymous with different amino acids for both camel species. The non-synonymous changes involved substitutions of valine with isolucine at $\mathrm{G}_{118} \rightarrow \mathrm{A}_{118}$, histidine with tyrosine at $\mathrm{C}_{145} \rightarrow \mathrm{T}_{145}$, glutamine with arginine at $\mathrm{A}_{158} \rightarrow \mathrm{G}_{158}$, alanine with threonine at $\mathrm{G}_{340} \rightarrow$ $\mathrm{A}_{340}$ which was characteristic to Saudi camel individual and methionine with threonine at $\mathrm{T}_{563} \rightarrow \mathrm{C}_{563}$ (Fig. 3). The inbreed changes involved 6 synonomyous substitutions without discrimination between racing and production. However, only one non-synonymous change was found in which alanine in Saudi breed was replaced with threonine in Dubai and Moroccan breeds $\left(\mathrm{G}_{340} \rightarrow \mathrm{A}_{340}\right)$.

The substitutions of the 966 base pair that have been sequenced for cytb gene in this study were analyzed. Ninety seven substitutions were recorded between the two species of which 90 were transitions and 7 were transversions. Within these variations, 7 were nonsynonymous which involved substitutions of serine with leucine at $\mathrm{G}_{330} \rightarrow \mathrm{A}_{330}$, valine with isoleucine at $\mathrm{G}_{352} \rightarrow$ $A_{352}$, alanine with isoleucine at $\mathrm{G}_{712} \rightarrow \mathrm{A}_{712}$, valine with isoleucine at $\mathrm{G}_{883} \rightarrow \mathrm{A}_{883}$, phenylalanine with leucine at $\mathrm{T}_{907} \rightarrow \mathrm{C}_{907}$, alanine with methionine at $\mathrm{G}_{916} \rightarrow \mathrm{A}_{916}$ and threonine with methionine at $\mathrm{G}_{945} \rightarrow \mathrm{A}_{945}$ (Fig. 4). The changes within the Arabian breed involved 13 synonymous substitutions of which only one was transversion discriminating one racing individual. 
Mohamed M. Ahmed / American Journal of Biochemistry and Biotechnology 9 (1) (2013) 61-70

Table 2. The sequenced fragments of the studied genes and the intra and inter-specific nucleotide and amino acid substitutions

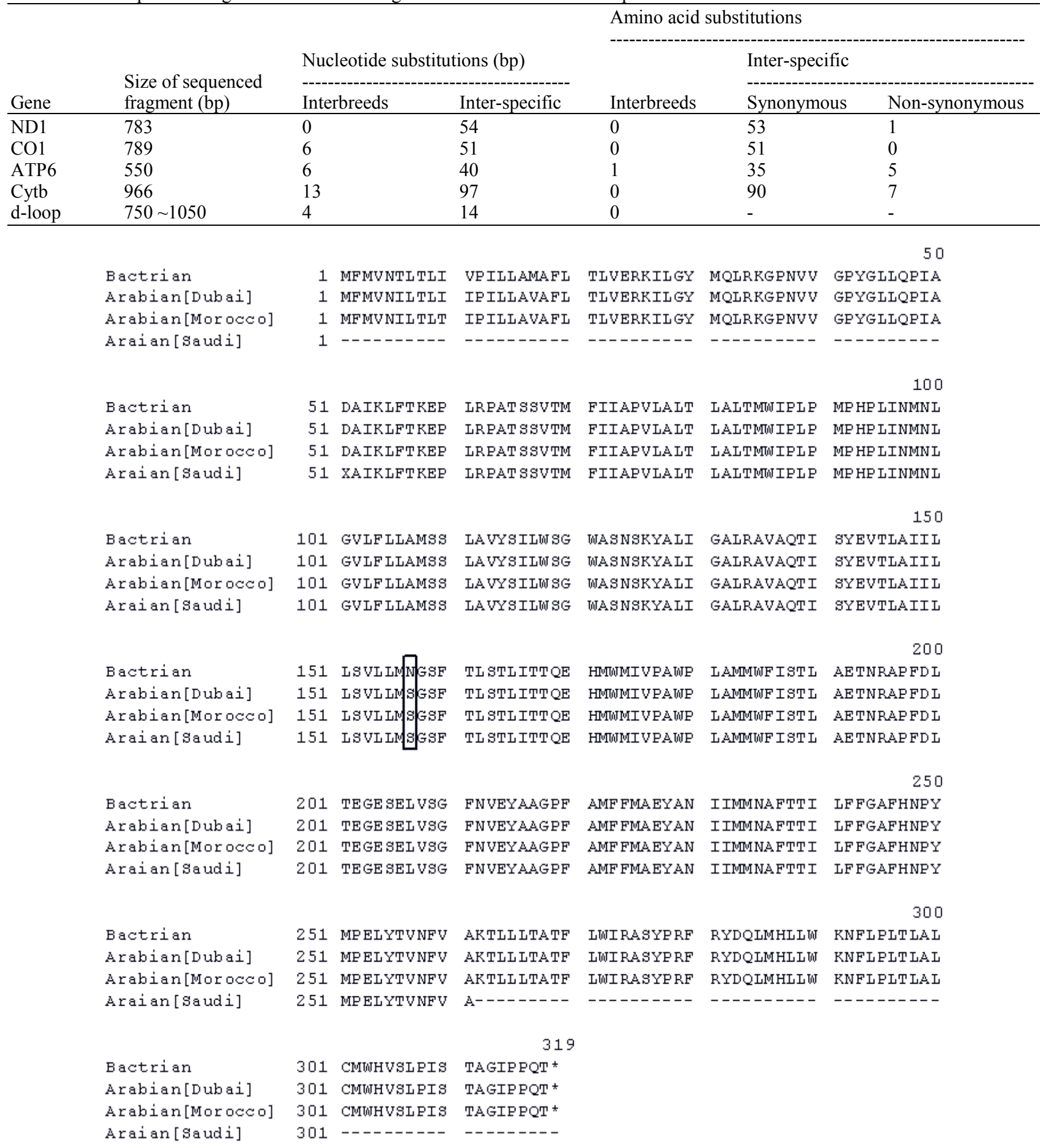

Fig. 1. The aligned translated amino acids of the sequenced ND1 gene for Bactrian camel and the different haplotypes of the Arabian camel. The letters inside the box are polymorphic among taxa. Note that the data for taxa other than Saudi one were obtained from the GenBank database. The data of all taxa other than Saudi one are for the complete gene sequence. 
Mohamed M. Ahmed / American Journal of Biochemistry and Biotechnology 9 (1) (2013) 61-70

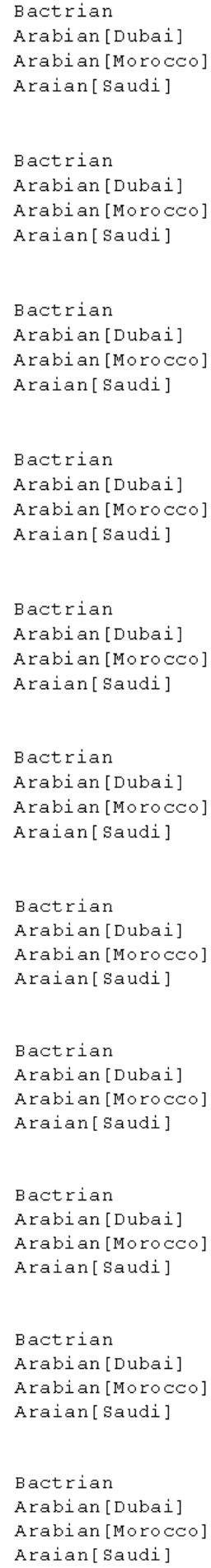

DQI YNWVTA HAFVMIEFMV MEIMI GGEGN WLVPLMI GAP DMAFERINNM DQIYNWVYA A HAFVMIEFMV MEIMI GGFGN WLVPLMI GAP DIMAFERIMNM DQIYNWWTA HAF VMIEFMV MPIMIGGFGN WULVPLMI GAP DMAFERMINM DQI YNVVVTA HAFVMIEFMV MPIMIGGFGN WLVPLMIGAP DMAFPRMNM

SETILIEAEL LLLASSMVEA GAGTGWTVYP PLACNAAHA ASVDLTIFSL GETLLPEATL LLLASIMVEA GAGTGNTVYP PLAGNLAHAG ASVDLTIFSL SETLLPESL LLLASEMVEA GAGTGWTVYP PLAGNLAHAG ASVDLTIESL SETLLPPSEL LLLASSMVEA GAGTGUTVYP PLAGNLAHAG ASVDLTIESL

HLAGVEILG AINEITTIIN MRPPAMEQY TPLFVUVI TAVLLLLIE HLAGVEILG AINEITTIIN MKPPAMSQY TEL TVWEVI TAVLLLLEL HLAGVSILG AINEITTIIN MKPPAMSQYQ TELEVWVII TAVLLLLIE HLAGVSILG AINEITTIIN MKPPAMSQYQ TPLEVUSLI TAVLLLLSLP

VLAAGITMLI TDRNLNTTEE DEAGGGDIL YQHLEWEGH PEVYILILPG VLAAGITMLI TDRNLNTTEF DEAGGGDPIL YOHLFWEFGH PEVYILILPG VLAAGITMLL TDRNLNTTEF DEAGGGDPIL YOHLFWEFG PEVYILILPG VLAAGITMLI TDRNLNTTEE DEAGGGDIL YOHLENEGH PEVYILILPG

300 FGMISHIVTY YSGKREPFGY MGMVTAMMSI GELGE IVTAH HMETVGMDVD FGMISHIVTY YSGKREPFGY MGMVTAMMSI GELGE IVWAH HMF TVGMDVD FGMISHIVTY YSGKREPFGY MGMVTAMMS I GELGEIVITAH HMETV-----

$$
3.50
$$

TRAYFTSATM IIAIPTGVKV FSTLATLHGG NIKTSPAML何 ALGEIFLFTV TRAYFTSATM IIAIFTGVKV FSTLATLHGG NIKTSFAMLTI ALGFIFLFTV TRAYFTSATM IIAIFTGVKV FSTLATLHGG NIKTS PAMLTI ALGFIFLFTV

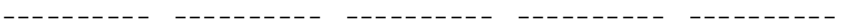

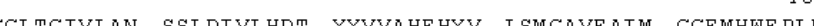
GGLTGIVLAN GSLDIVLHDT YYVVAHEHYV LGMGAVEAIM GGEMHNE PLF GGLTGIVLAN SSLDIVLHDT YYVVAHEHYV LSMGAVEAIM GGEMHWELF $--------$ SGYTIDDTWA KIQFAIMEVG VNLTFEFQHF LGLGGMRRY SDYPDAYTTW GGYTIDDTWA KIQFAIMEVG VNLTFEPQHF LGL GGMPRR SDYPDAYTTU SGYTIDDTWA KIQFAIMFVG VNLTFFPQHF LGLGGMPRRY SDYPDAYTTW

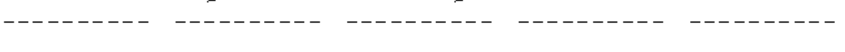
MTISSVGSEI SLTAVVLMVE IVIEAAEASRR EVTTVELTAT NLEWLHGCPE NTISSVGSE I SLTAVVLMVE IVWEAEASKR EVTTVELTAT NLEWLHGCPP NTISSVGSFI SLTAVVLMVE IVWEAEASRR EVTTVELTAT NLEWLHGCPP

\begin{tabular}{ll} 
& 515 \\
PYHTEEEPTY & INLK* \\
PYHTEEETTY & INLK \\
PYHTEEETTY & INLK \\
\hline------ & ----
\end{tabular}

Fig. 2. The aligned translated amino acids of the sequenced CO1 gene for Bactrian camel and the different haplotypes of the Arabian camel. Note that the data for taxa other than Saudi one were obtained from the GenBank database for the complete gene sequence 
Mohamed M. Ahmed / American Journal of Biochemistry and Biotechnology 9 (1) (2013) 61-70

Bactrian
Arabian [Dubai]
Arabian [Morocco]
Araian [Saudi]
Bactrian
Arabian [Dubai]
Arabian [Morocco]
Araian [Saudi]

Bactrian
Arabian [Dubai]
Arabian [Morocco]
Araian [Saudi]

Bactrian
Arabian [Dubai]
Arabian [Morocco]
Araian [Saudi]
Bactrian
Arabian [Dubai]
Arabian [Morocco]
Araian [Saudi]

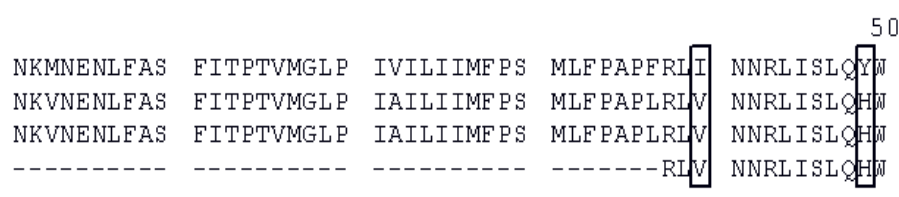
LIRETSKQMM TIHNHKGQTW SLMLMSLIMF IGTTNLLGLL PHSFTPTTQL LIQLTSKMM TIHNHKGQT⿰亻丨 SLMLMSLIMF IGTTNLLGLL PHSETPTTQL L IOETSKMM TIHNHKGQTW SLMLMSLIMF IGTTNLLGLL PHSFTPTTQL LIQ⿴囗大 TKMM TIHNHKGQTW SLMLMSLIMF IGTTNLLGLL PHSETPTTQL

150

SMNLGMAIPL WAGTVTGER NKTKASLAHF LPQGTPTPLI PMLVIIETIS SMNLGMAIPL WAGTVTGER NKTKASLAHE LPQGTPTPLI PMLVIIETIS SMNLGMAIPL WAGTVTGER NKTKASLAHF LPQGTPTPLI PMLVIIETIS SMNLGMAIPL WAGAVTGER NKTKASLAHF LPQGTPTPLI PMLVIIETIS

LFIOPVALAV RLTANITAGH LLMHLIGGAT LALMSINTPT ALITFIVLIL LFIQPVALAV RLTANITAGH LLMHLIGGAT LALMSINMET ALITEIVLIL LFIQPVALAV RLTANITAGH LLMHLIGGAT LALMSINMET ALITEIVLIL LFIQPVALAV RLTANITAGH LLMHLIGGAT LALMSINMPT ALITFIVLIL

\section{9}

LTILEFAVAM IQAYVETLLV SLYLHDNT*

LTILEFAVAM IQAYVFTLLV SLYLHDNT*

LTILEFAVAM IQAYNETLLV SLYLHDNT*

LTILEFAVAM IOANETLLV

Fig. 3. The aligned translated amino acids of the sequenced ATP6 gene for Bactrian camel and the different haplotypes of the Arabian camel. The letters inside the boxes are polymorphic among taxa. Note that the data for taxa other than Saudi one were obtained from the GenBank database for the complete gene sequence. The underlined column was a SNP discriminating the Saudi haplotype from other Arabian ones

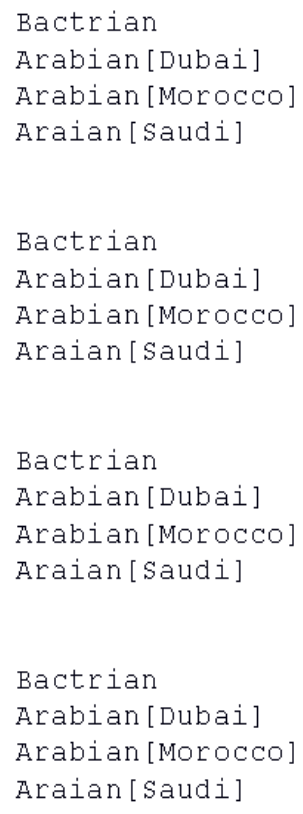

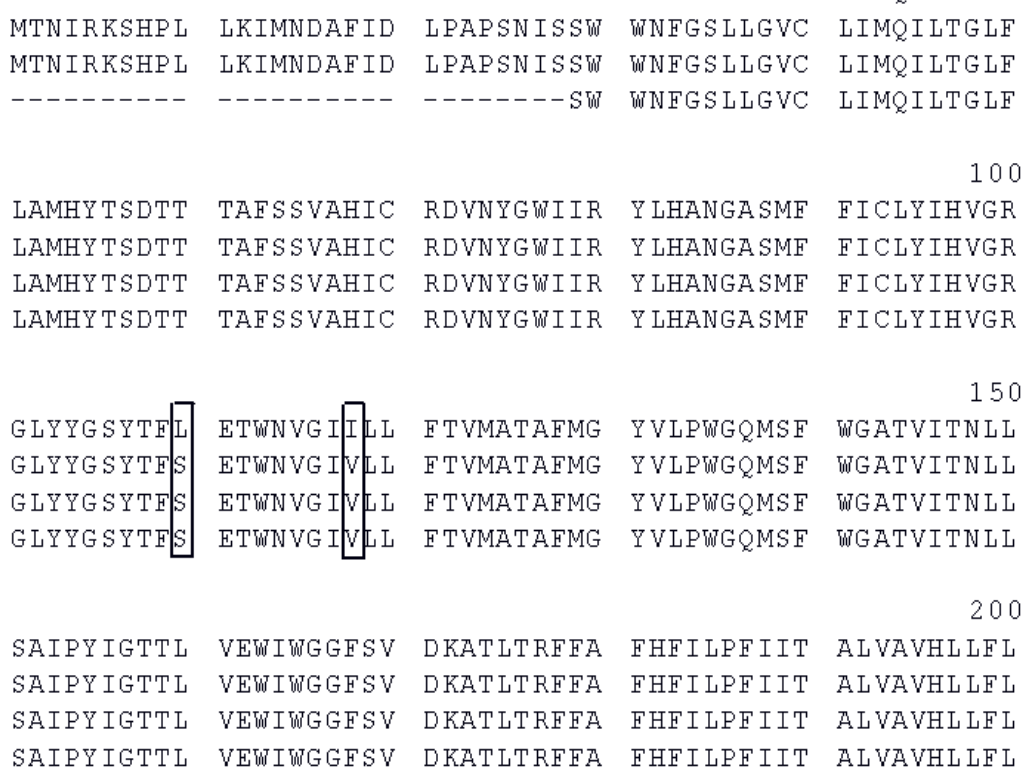

SAIPYIGTTL VEWI WGGEV DKATLTRFA FHFILPFIIT ALVAVHLLFL

SAIPYIGTTL VEWIWGGFV DKATLTRFFA FHFILPFIIT ALVAVHLLFL

SAIPYIGTTL VEWIWGGFS DKATLTRFFA FHFILPFIIT ALVAVHLLFL SAIPYIGTTL VEWIWGGSV DKATLTRFFA FHFILPFIIT ALVAVHLLFL 


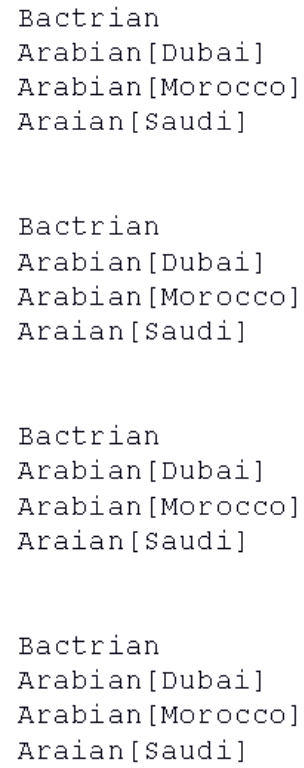

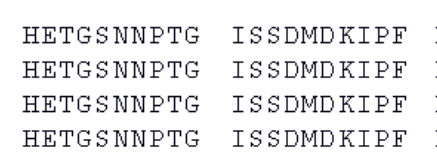

HETGSNNPTG ISSDMDKIPF 
changes within the two structural classes of nucleotides (purines and pyrimidines), that is, in terms of transitions and transversions.

As ND1 is the start point for energy transduction (Bridges et al., 2010) and shows high mutations during abnormal cases such as oxidative stress and aging (DiMauro and Schon, 2003), we may consider that the little difference between Arabian and Bactrian camels was due to similar biochemical roles of this protein in both camel species.

The variations occurred in CO1 gene among all samples either inter-specific or intra-specific were in the third position with no amino acid changes. CO1 data therefore supported the stability of this gene in both camel species. Moreover, cytochrome $\mathrm{C}$ oxidase is the terminal complex of the electron transport chain and is activated to prevent an excessive buildup of reactive oxygen species (Chen et al., 2009). It is also not affected by the variation in the respiratory capacity (Devin and Rigoulet, 2007). These two reasons may explain the similarity in the amino acid contents of the gene coding for this protein in both camel species.

ATP6 gene showed great variation between the two camel species and therefore, it could be considered as an important marker to study the possible physiological differences between Arabian and Bacterian camels. In the cell, ATP metabolism is catalyzed by enzymes known as ATP synthases and ATPases, respectively. ATPase ensures the work of muscular proteins, biosynthetic reactions, ion transfer across biological membranes and other energy-consuming processes due to the energy results from ATP hydrolysis. The synthesis of ATP is catalyzed by ATP synthases using the energy from external sources. One type of ATP synthase complexes catalyzes both reactions, ATP synthesis and ATP hydrolysis (Romanovsky and Tikhonov, 2010). As one of ATP synthase complexes performs synthesis of the majority of ATP molecules in the cell (Skulachev, 1988; Feldkamp et al., 2005; Nelson and Cox, 2004) and the phenotype of both camel species are clearly different, the great amino acid substitutions of ATP6 gene may be correlated to its major role in energy synthesis.

Cytb gene showed the greatest variation between the two camel species and therefore, it could be considered as the most important marker to study the possible energy related adaptations for both Arabian and Bacterian camels. The hydrophilic protein of cytochrome $\mathrm{b}$ acquires higher mutations in abnormal cases of skeletal muscle weakness and exercise intolerance (Andreu et al., 1999; Fernandez-Vizarra et al., 2007). It is one of the cytochromes which showed variations when the respiratory capacity changes (Devin and Rigoulet, 2007). We therefore may correlate the highest amino acid substitutions of this gene to the great variation in the respiratory capacity of both camels.

There was an obvious repeat at the 3 ' of the d-loop region. We did not find an interpretation to this repeat, in spite of, such repeat has been described for other vertebrates in this region (Moritz and Brown, 1987; Lunt et al., 1998). Brearley and Zhou (2001) agreed with Dionne et al. (1991) and Rivera et al. (1998) in that there was no significant relationship between d-loop polymorphism and either oxygen consumption or endurance. The discrepancy between these findings and those of Chen et al. (2000) may be explained by the fact that the d-loop region is known to vary between populations (Horai and Hayasaka, 1990). Based on these arguments, we could not be able to relate the polymorphism in the d-loop repeat of both production and racing camels to the difference in the maximum oxygen consumptions which is usually high in those reared for racing.

\section{CONCLUSION}

The energy-related mitochondrial genes showed amino acid substitutions increased according to their roles in energy metabolism in both Arabian and Bactrian camels. These substitutions seemed to be correlated with the energy metabolism in both camel phenotypes. ATP6 acquired the greatest changes because it controls the majority of energy production. Cytb in the inner mitochondrial membrane came the second in such substitutions. Because CO1 is responsible for free radicals scavenging and considered as the terminal complex of the electron transport chain of the inner mitochondrial membrane, it showed no substitutions. The d-loop showed polymorphism between both species without any evidence relates such variation to energy production.

\section{REFERENCES}

Abdel-Fattah, M., H. Amer, M.A. Ghoneim, M. Warda and Y. Megahed, 1999. Response of one-humped camel (Camelus dromedarius) to intravenous glucagon injection and to infusion of glucose and volatile fatty acids and the kinetics of glucagon disappearance from the blood. Zentralbl Veterinarmed A, 46: 473-481. PMID: 10596286 
Al-Swailem, A.M., M.M. Shehata, F.M. Abu-Duhier, E.J. Al-Yamani and K.A. Al-Busadah et al., 2010. Sequencing, analysis and annotation of expressed sequence tags for Camelus dromedarius. PLoS ONE, 5: e10720-e10720. PMID: 20502665

Andreu, A.L., M.G. Hanna, H. Reichmann, C. Bruno and A.S. Penn et al., 1999. Exercise intolerance due to mutations in the cytochrome $b$ gene of mitochondrial DNA. N Engl. J. Med., 341: 10371044. PMID: 10502593

Asakawa, S., Y. Kumazawa, T. Araki, H. Himeno and K. Miura et al., 1991. Strand-specific nucleotide composition bias in echinoderm and vertebrate mitochondrial genomes. J. Mol. Evol., 32: 511-520. PMID: 1908022

Brearley, M.B. and S. Zhou, 2001. Mitochondrial DNA and maximum oxygen consumption. Southern Cross University.

Bridges, H.R., I.M. Fearnley and J. Hirst, 2010. The subunit composition of mitochondrial NADH: Ubiquinone oxidoreductase (complex I) from Pichia pastoris. Mol. Cel. Proteom., 9: 2318-2326. PMID: 20610779

Burton, M., 1972. The World Encyclopedia of Animals. 2st Edn., World Publishing Company, New York, pp: 400.

Chen, Q., L.H. Ma and J.Q. Chen, 2000. Analysis on genetic polymorphism of mtDNA in endurance athletes and sedentary subjects. Zhongguo Ying Yong Sheng Li Xue Za Zhi, 16: 327-330. PMID: 11236691

Chen, Y.F., C.H. Kao, Y.T. Chen, C.H. Wang and C.Y. Wu et al., 2009. Cisd 2 deficiency drives premature aging and causes mitochondria-mediated defects in mice. Genes Dev., 23: 1183-1194. PMID 19451219

Clayton, D.A., 1996. Mitochondrial DNA Replication. In: DNA Replication in Eukaryotic Cells, DePamphilis, M.L. (Ed.), Cold Spring Harbor Laboratory Press, ISBN-10: 0879694599, pp: 10151027.

Cockrill, R., 1984. The camelid: An all-purpose animal. Proceedings of the Khartoum Workshop on Camels, (KWC' 79), Scandinavian Institute of African Studies, pp: 197-199. DOI: 10.7202/701981ar

Devin, A. and M. Rigoulet, 2007. Mechanisms of mitochondrial response to variations in energy demand in eukaryotic cells. Am. J. Physiol. Cell Physiol., 292: C52-C58.

DOI: 10.1152/ajpcell.00208.2006
DiMauro, S. and E.A. Schon, 2003. Mitochondrial respiratory-chain diseases. N Engl. J. Med., 348: 2656-2668. DOI: 10.1056/NEJMra022567

Dionne, F.T., L. Turcotte, M.C. Thibault, M.R. Boulay and J.S. Skinner et al., 1991. Mitochondrial DNA sequence polymorphism, VO2max and response to endurance training. Med. Sci. Sports Exerc., 23: 177-185. PMID: 1673216

Duehlmeier, R., K. Sammet, A. Widdel, W.V. Engelhardt and U. Wernery et al., 2007. Distribution patterns of the glucose transporters GLUT4 and GLUT1 in skeletal muscles of rats (Rattus norvegicus), pigs (Sus scrofa), cows (Bos taurus), adult goats, goat kids (Capra hircus) and camels (Camelus dromedarius). Comp. Biochem. Physiol., 146: 274-282. DOI: 10.1016/j.cbpa.2006.10.029

Elmahdi, B., H.P. Sallmann, H. Fuhrmann, W.V. Engelhardt and M. Kaske, 1997. Comparative aspects of glucose tolerance in camels, sheep and ponies. Comp. Biochem. Physiol. Part A: Physiol., 118: 147-151. PMID: 9243815

Emmanuel, B. and A. Nahapetian, 1980. Fatty acid composition of depot fats and rumen wall of the camel (Camelus dromedarius. Comparative Biochem. Physiol. Part B: Biochem. Mol. Biol., 67: 701-704. DOI: 10.1016/0305-0491(80)90435-6

Feldkamp, T., A. Kribben and J.M. Weinberg, 2005. F1FO-ATPase activity and ATP dependence of mitochondrial energization in proximal tubules after hypoxia/reoxygenation. J. Am. Soc. Nephrol., 16: 1742-1751. PMID: 15843467

Fernandez-Vizarra, E., M. Bugiani, P. Goffrini, F. Carrara and L. Farina et al., 2007. Impaired complex III assembly associated with BCS1L gene mutations in isolated mitochondrial encephalopathy. Hum. Mol. Genet., 16: 1241-1252. PMID: 17403714

Fonseca, R.R.D., W.E. Johnson, S.J. O’Brien, M.J. Ramos and A. Antune, 2008. The adaptive evolution of the mammalian mitochondrial genome. BMC Genom., 9: 119-119. DOI: 10.1186/1471-2164-9119

Hassanin, A., F. Delsuc, A. Ropiquet, C. Hammer and B.J.V. Vuuren et al., 2012. Pattern and timing of diversification of cetartiodactyla (mammalia, laurasiatheria), as revealed by a comprehensive analysis of mitochondrial genomes. C R Biol., 335: 32-50. DOI: 10.1016/j.crvi.2011.11.002 
Holler, H., G. Breves, M. Lechner-Doll and E. Schulze, 1989. Concentrations of volatile fatty acids and acetate production rates in the forestomachs of grazing camels. Comp. Biochem. Physiol. Part B: Comp. Biochem., 93: 413-416. DOI: 10.1016/03050491(89)90101-6

Horai, S. and K. Hayasaka, 1990. Intraspecific nucleotide sequence differences in the major noncoding region of human mitochondrial DNA. Am. J. Hum. Genet., 46: 828-842. PMID: 2316527

Huang, X., R.S. Shah and K.A. Khazanehdari, 2007. Complete nucleotide sequence of mitochondrial genome of the dromedary camel, camelus dromedarius: Structure and the control region.

Ji, R., P. Cui, F. Ding, J. Geng and H. Gao et al., 2009. Monophyletic origin of domestic bactrian camel (Camelus bactrianus) and its evolutionary relationship with the extant wild camel (Camelus bactrianus ferus). Anim. Genet., 40: 377-82. DOI: 10.1111/j.1365-2052.2008.01848.x

Kadim, I.T., O. Mahgoub, R.S. Al-Maqbaly, K. Annamalai and D.S. Al-Ajmi, 2002. Effects of age on fatty acid composition of the hump and abdomen depot fats of the Arabian camel (Camelus dromedarius). Meat Sci., 62: 245-251. DOI: 10.1016/S0309-1740(01)00254-6

Kaske, M., B. Elmahdi, W.V. Engelhardt and H.P. Sallmann, 2001. Insulin responsiveness of sheep, ponies, miniature pigs and camels: Results of hyperinsulinemic clamps using porcine insulin. J. Comp. Physiol. B, 171: 549-556. PMID: 11686613

Lunt, D.H., L.E. Whipple, B.C. Hyman, 1998. Mitochondrial DNA Variable Number Tandem Repeats (VNTRs): Utility and problems in molecular ecology. Mol. Ecol., 7: 1441-1455. PMID: 9819900

Moritz, C. and W.M. Brown, 1987. Tandem duplications in animal mitochondrial DNAs: Variation in incidence and gene content among lizards. Proc. Natl. Acad. Sci. USA., 84: 7183-7187. PMID: 3478691
Nelson, D. L. and M.M. Cox, 2005. Lehninger Principles of Biochemistry. 4th Edn., W. H. Freeman, New York, ISBN-10: 0716743396, pp: 1100.

Nicholls, D., 2002. Mitochondrial bioenergetics, aging and aging-related disease. Sci. Aging Knowl. Environ., 31: 12-12. PMID: 14603000

Rivera, M.A., B. Wolfarth, F.T. Dionne, M. Chagnon and J.A. Simoneau et al., 1998. Three mitochondrial DNA restriction polymorphisms in elite endurance athletes and sedentary controls. Med. Sci. Sports Exerc., 30: 687-690. PMID: 9588609

Romanovsky, Y.M. and A.N. Tikhonov, 2010. Molecular energy transducers of the living cell. Proton ATP synthase: A rotating molecular motor. Phys. Usp., 53: 893-914.

DOI: 10.3367/UFNe.0180.201009b.0931

Schmidt-Nielsen, K., 1979. Desert Animals: Physiological Problems of Heat and Water. 1st Edn., Dover Publications, New York, ISBN-10: 0486238504, pp: 277.

Shadel, G.S. and D.A. Clayton, 1997. Mitochondrial DNA maintenance in vertebrates. Ann. Rev. Biochem., 66: 409-35. PMID: 9242913

Shirazi-Beechy, S.P., I.S. Wood, J. Dyer, D. Scott and T.P. King, 1994. Ruminant physiology: Digestion, metabolism, growth physiology and reproduction. Proceedings of the 8th International Symposium on Ruminant Physiology, (ISRP' 94).

Skulachev, V.P., 1988. Membrane Bioenergetics. 1st Edn., Springer-Verlag, Berlin, ISBN-10: 0387183353, pp: 442.

Zierath, J.R., A. Krook and H. Wallberg-Henriksson, 1998. Insulin action in skeletal muscle from patients with NIDDM. Mol. Cel. Biochem. 182: 153-160. PMID: 9609124 